\title{
China's Growth: Can Goldilocks Outgrow Bears?
}




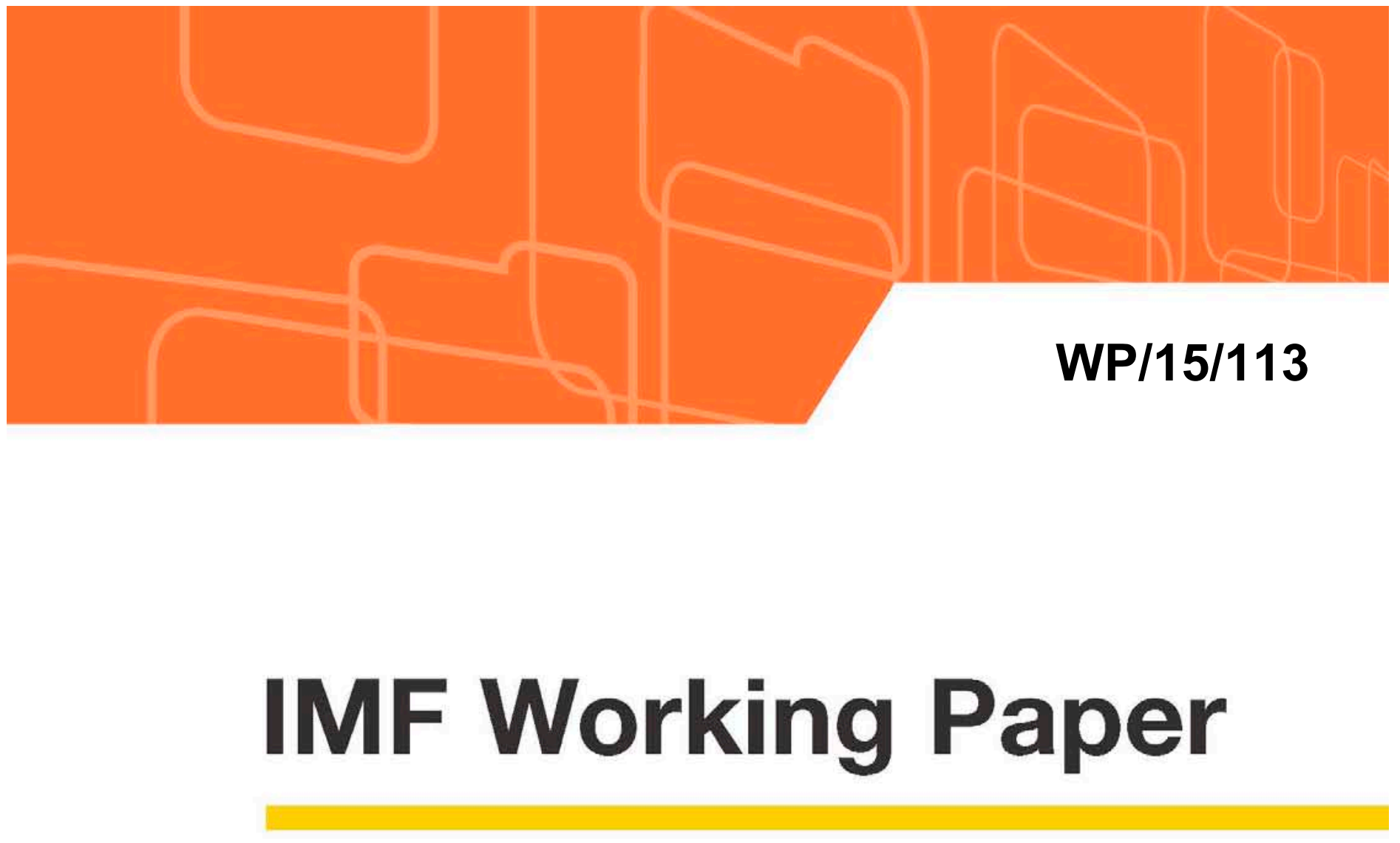

\title{
China's Growth: Can Goldilocks Outgrow Bears?
}

\author{
Wojciech Maliszewski and Longmei Zhang
}




\title{
IMF Working Paper
}

Asia and Pacific Department

\section{China's Growth: Can Goldilocks Outgrow Bears? ${ }^{1}$ \\ Prepared by Wojciech Maliszewski and Longmei Zhang}

Authorized for distribution by Steve Barnett

May 2015

\section{This Working Paper should not be reported as representing the views of the IMF.} The views expressed in this Working Paper are those of the author(s) and do not necessarily represent those of the IMF or IMF policy. Working Papers describe research in progress by the author(s) and are published to elicit comments and to further debate.

\begin{abstract}
The paper analyzes the recent growth dynamics in China, evaluating both cyclical positions and long-term growth prospects. The analysis shows that financial cycles play a more important role than traditional inflation-based cycles in shaping the dynamics of growth. Currently, the 'finance-neutral' gap - our measure of the financial cycle - is large and positive, reflecting imbalances accumulated in the economy since the Global Financial Crisis. A period of slower growth is therefore both likely and needed in the near term to restore the economy to equilibrium. In the medium term, growth will slow as China moves closer to the technology frontier, but a steadfast implementation of reforms can ensure that China follows the path of the "Asia Tigers" and achieves successful convergence to high-income status.
\end{abstract}

JEL Classification Numbers: O11, O47

Keywords: China, potential growth, total factor productivity, output gap

Authors’ E-Mail Addresses: wmaliszewski@imf.org; lzhang2@imf.org

\footnotetext{
${ }^{1}$ We are grateful to Steve Barnett, Olivier Blanchard, Nigel Chalk, Stanislaw Gomulka, Papa N'Diaye, Nathan Porter, Lukasz Rachel, Markus Rodlauer and participants in the ECB workshop 'China-Transitioning Towards a Sustainable Economy’ for comments, to Sung Eun Jung for excellent research assistance.
} 


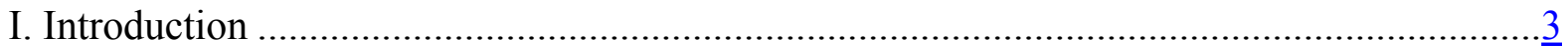

II. 'Asiaphoria’ Meets 'The Myth of Asia's Miracle' ........................................................

III. Estimating Potential Output and Output Gap in China ................................................... $\underline{5}$

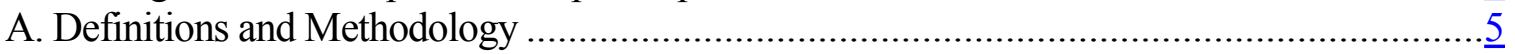

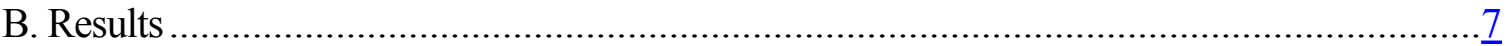

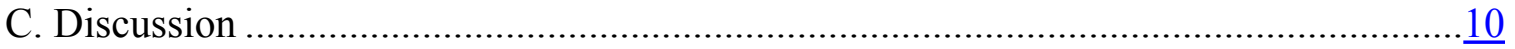

IV. Cross-Country Perspective: Catching Up with Asian Tigers? ....................................12

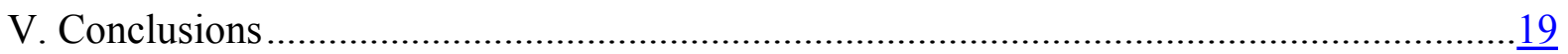

A. Univariate Filters....................................................................................

B. Multivariate Filters Linking Output Gap to Inflationary Pressures ........................... $\frac{22}{24}$

C. Multivariate Filter with the Addition of a Production Function ..................................24

D. Multivariate Filter to Estimate 'Finance-Neutral' Output Gap...................................26

E. Production Function Approach for Cross-Country Analysis ...................................

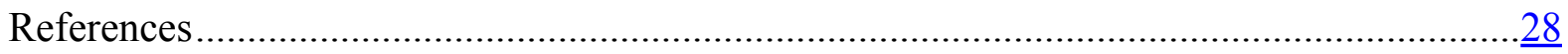

Figures

1. Univariate Filters

2. Multivariate Filters......................................................................................... $\frac{8}{9}$

3. Production Function Filter ............................................................................... $\frac{9}{9}$

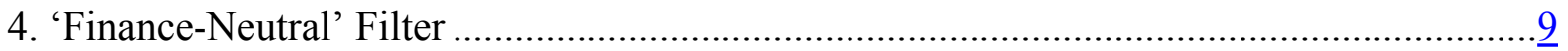

5. Catching Up Process Relative to Fast-Growing Asia ...............................................13

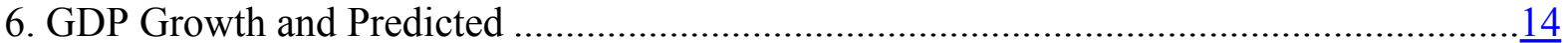

7. Contributions to Growth and Investment Shares ....................................................... $\frac{17}{18}$

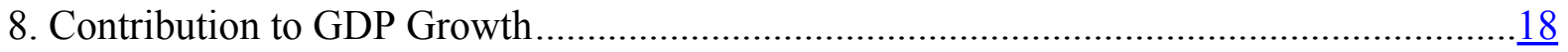

Appendix

Methodology. 


\section{INTRODUCTION}

China's impressive growth record speaks for itself, and the country's policymakers have won additional accolades for the timely response to the Global Financial Crisis. The Chinese GDP has been growing at the average rate of nearly 10 percent per year in the past four decades. The well-timed policy relaxation supported growth in the immediate aftermath of the crisis. Several analysts pronounced the arrival of a goldilocks economy in China - not too hot to fuel inflation and not too cold to slip into recession (JPMorgan, 2009) - and some see a continuation of the stable economic growth as the most likely scenario for China.

But the past success is no guarantee of future performance, and fears are rising among China 'bears' that the recent deceleration in economic activity is a prelude to a deeper growth slowdown (Xie, 2013). These fears are fed by the observation that the surge in credit-financed investment in response to the Global Financial Crisis (GFC) has pushed credit up to, and even beyond, the point that has typically led to sharp growth slowdowns and banking crises in other countries (Liao and Maliszewski, 2015). The surge has also been linked to a boom in the real estate activity, supporting several sectors of the economy at the expense of growing inventories of unsold houses and a rising leverage in the sector. The spectrum of overinvestment or 'malinvestment' looms large, with a possibility of a sharp correction when demand created by the investment boom evaporates and the leverage proves unsustainable.

A key question is how much of China's slowdown is temporary (cyclical) versus long lasting (structural). Growth fluctuations in developing and emerging markets often follow a pattern of spans of impressive growth followed by long periods of stagnation. The concern is therefore not only about a cyclical growth slowdown typically experienced by mature economies, but a prolonged slump so often experienced in emerging markets. These fears are also fed by the observation that structural 'imbalances' in the Chinese economy-exceptionally high investment rates associated by some with 'forced savings' (Eckaus, 2014) - have further grown since the GFC, reducing investment efficiency and total factor productivity (TFP) growth.

We contribute to the ongoing growth debate by identifying the cyclical position and assessing the degree of potential output slowdown in China. Our main results are:

- We expect growth to slow down in the near-term. Financial cycles in China play a significant role in shaping growth dynamics, and the economy is now likely near the peak of a powerful cycle propelling the economy since the GFC. An adjustment is therefore both likely and needed to bring the economy closer to equilibrium.

- Potential growth is slowing. This is expected as China makes progress on the long journey of converging to advanced economy income levels. As it moves closer to this technology frontier, growth will continue to slow. However, the pace of convergence, and thus China's medium-term growth rate, will depend on structural reforms. With success in implementing reforms, China can follow the historical experience of other fast-growing Asian economies. . 
The paper is organized as follows: we start from key themes in the recent literature on China's growth performance; we then discuss and motivate the range of methods to estimate potential output and output gap, and present and discuss results; we finish with international comparisons, contrasting the performance of fast growing economies against China's own. The last section offers broad policy recommendations.

\section{II. 'ASIAPHORIA' MEETS 'THE MYTH OF ASIA'S MIRACLE'}

Time and again economic developments in Asia spark a lively debate on the regional growth performance. A couple of years before the Asian Crisis, several authors examined growth in fastgrowing Asian economies only to reach starkly different conclusions about their prospects. Page (1994) found the growth performance significantly better compared to other regions, attributing the 'Asian Miracle' to factor accumulation combined with the efficient allocation reflected in relatively high TFP growth. In “The Myth of Asia's Miracle," Krugman (1994) famously debunked this view, drawing a parallel between seemingly uninterrupted industrial growth in the Soviet Union and the rise of Asian economies. He concluded that growth rates in both systems were largely input-driven - based on an extraordinary 'willingness' to save and sacrifice current consumption for the sake of future production - with little productivity improvement. In this view, fast-growing Asian economies were bound to slow down, and a naive projection of the past growth rates into the future was likely to overstate real prospects. Young (1995) reached a similar conclusion, documenting the fundamental role played by factor accumulation in explaining the extraordinary postwar growth of Hong Kong SAR, Singapore, South Korea and Taiwan Province of China. With the benefits of the hindsight, both bears and bulls could claim partial victory: tremors of the Asian Crisis were only a couple years ahead, but Singapore - seemingly a prime example of Soviet-style development in Krugman (1994) — is now ahead of the US in terms of income per capita and human development indicators.

Not surprisingly, China's impressive growth performance has been analyzed from the same angle - has it been a result of factor accumulation or TFP growth? No clear consensus has emerged in the literature, which reports a wide range of estimates and a significant variation in the TFP growth over time. A meta-study by Xu and Xiaohua (2012) summarizes reports from 150 academic studies. They conclude that the mean reported TFP growth between 1978 and 2009 is about 2 percent, contributing around 20 percent to the GDP growth in this period. But there is a significant uncertainty about both the level and the trend. Fluctuations in the TFP dynamics were large, ranging from about 1 percent on average in 1985-89 and 1995-1999 periods, to between $4 \frac{1}{2}$ and 5 percent in the remainder of the sample. The standard deviation of estimates is also very high (from 5 to 10 percent) and negative values for the TFP growth are reported in all sub-samples. More recent studies report lower average productivity growth. Zhan, Jiang and Wang (2014) estimate TFP growth of about 1.5 percent in the 1998-2012 sample, although they observe a modest pickup in the last two years of the sample to about $2 \frac{1}{4}$ percent. In another recent study, $\mathrm{Wu}$ (2014) questions official National Accounts data and shows that his alternative GDP series implies a negative TFP growth in the 2008-12 period. 
The recent TFP slowdown in China has revived the old debate on growth prospects. A set of statistics recently put together by Pritchett and Summers (2014) shows that the most robust finding about growth performance is its reversion to the mean. From this perspective, the impressive growth in China is already an anomaly. Using variants of a simple 'mean-correction' model they estimate that growth rates in the range of 4-5 percent are likely for China at the end of the next decade. Faster growth is possible, but unlikely in their view given historical experience of a wide range of economies. Moreover, they also argue that growth episodes in developing countries are often punctured by sharp drop-offs, and that salient characteristics of the Chinese economy - the high level of state control and corruption in their view - makes such a sharp dropoff likely. Wu (2014) and Hoffman and Polk (2014) find TFP growth in China falling steeply in post-GFC years, with the allocation of capital becoming less efficient after the prolonged investment boom (which is also reflected in falling incremental capital to output ratio (ICOR) and the marginal return to capital). China, in their view, faces a perspective of a deep structural slowdown, ultimately down-shifting China's trend growth rate to the 4 percent range, in line with Pritchett and Summers (2014) estimates.

There has been comparatively less technical work on cyclical fluctuations in output and its implications for the near-term economic growth. Past studies focused on the usefulness of output gap measures for guiding monetary policy in China, particularly in the context of frequent bouts of inflation. Traditional time-series filters, Phillips-curve-based multivariate filters, and the production function approach have been applied and compared in the past (Scheibe, 2003; Gerlach and Peng, 2006), but there are very few studies covering the post-GFC period. Zhang and others (2013) apply and compare traditional Hodrick-Prescott and band pass filters with a multivariate Beveridge-Nelson decomposition using 1980-2010 data. The multivariate methodwhich utilizes additional information embedded in the dynamics of inflation, money, and the effective exchange rate - produces significantly different (and according to the authors superior) results in identifying cyclical fluctuations. All measures point to a moderate but positive output gap at the end of the sample in 2010, suggesting that the recent growth slowdown could have a cyclical component. In a recent study — and closely related to ours - Albert, Jude, and Rebillard (2015) show positive output gaps through 2014 using production function adjusted for a credit-driven (unsustainable) investment component.

\section{Estimating Potential Output and OutPut Gap in China}

\section{A. Definitions and Methodology}

We start from definitions of potential output and output gap. Traditionally, potential output is defined as the level of goods and services that the economy can produce on a sustained basis with existing resources without generating inflationary pressures. Output gap is then defined as the difference between the actual and potential output. While these definitions still play a key role in macro-policy formulation, the Global Financial Crisis (GFC) turned policymakers' attention to the link between fluctuations in output and credit cycles. A credit-fueled expansion of demand can prove unsustainable if, for instance, it is driven by anticipated higher future profits and these 
expectations are not realized. Such an expansion could be matched by a supply response, keeping inflationary pressures at bay and creating what on surface looks like a 'Goldilocks economy.' However, it can still mask an increase in financial imbalances, leading to a period of painful adjustment when expectations are revised, leverage has to be reduced, demand evaporates, and production factors are reallocated (the capital structure built during the expansion phase may have little use after the adjustment). The traditional definition of output gap does not capture such a link between financial and real cycles, and Borio and others (2014) proposed a measure of 'finance-neutral' potential output and a corresponding gap to account for it. This concept is also closely related to the work on financial instability hypothesis developed by Minsky (1986), and the Austrian interpretation of cyclical fluctuations as represented by Haberler (1932). We explore both traditional and 'finance-neutral' concepts of potential output and output gap. To better articulate the meaning of 'finance-neutral' measures, we refer to them as 'sustainable output' and 'a deviation from sustainable output' (used interchangeably with 'finance-neutral gap').

We apply a number of methods to estimate both traditional and finance-neutral measures of potential output and output gap.

- We start from univariate filters, which smooth GDP fluctuations to obtain estimates of potential output without any underlying economic theory. This includes the widely used Hodrick-Prescott filter and band-pass filters developed by Baxter and King (1995) and Christiano and Fitzgerald (1999). The Hodrick-Prescott filter estimates potential output by fitting a smooth trend to the data (where a pre-specified parameter governs a tradeoff between the fit of the trend line to the data and its 'smoothness'), while the band-pass filters remove cyclical fluctuations falling outside a pre-specified frequency band.

- We then turn to multivariate filters, which utilize information from other economic series to sharpen estimates of potential output. A bivariate version of the filter is a structural time series model linking temporary fluctuations in output to inflation, postulating that output gap is positively related to inflation pressures in line with the traditional theory behind the gap. An extended version of the model adds information about unemployment (exploiting the Okun's law), capacity utilization, and inflation expectations. These filters are more firmly based on the theory linking output gap to inflationary pressures, which makes them easier to interpret but potentially limits their usefulness if the impact of financial cycles is of interest.

- We proceed with a production function approach, which decomposes GDP into factors of production and smoothes them individually instead of filtering the GDP itself. A standard version of this method - presented later in the paper in the context of cross-country comparisons - applies the Hodrick-Prescott filter to labor and TFP inputs. Below we present a modified version, combining growth decomposition with a multivariate filter. It exploits both the information about the dynamics of individual factors of production and their utilization, and the information contained in inflation data (following the definition of potential output, defined as a situation when production factors are fully employed without generating inflationary pressures). 
- Finally, estimates of finance-neutral measures draw on the methodology developed by Borio and others (2014) but with important modifications. We link deviations from sustainable output to a credit gap — which is defined as a deviation of the real credit from its stochastic trend - rather than to changes in real credit as in Borio and others (2014). This formulation allows for a more intuitive interpretation of results: deviations from sustainable output remain positive for as long as the credit gap is open, and shrink to zero only when the process of deleveraging (closing the credit gap) is completed. We also assume that a similarly defined real house price gap (a deviation from stochastic trend) is affected by the credit gap, which helps to strengthen inference about the latter. Finally, unlike in Borio and others (2014), we do not impose restrictions on the variances of stochastic processes driving gaps, which allows for a more flexible inference about the amplitude of a deviation from sustainable output. Annex I discusses models and estimation methods in greater detail.

\section{B. Results}

This section discusses estimation results. All methods point to a secular slowdown in growth, but there are significant differences in the estimated potential rate of growth at the end of the sample, and in the size and even the sign of the output gap. For the ease of comparison, below we present all results against the Hodrick-Prescott measure. We focus on what is happening to potential output and output gap at the end of the sample to draw policy conclusions later in the paper

Standard Hodrick-Prescott filter indicates that potential growth slowed in the post-GFC period (Figure 1), but remains above the headline growth with a negative output gap. The trend growth at the end of the sample drops to about 8 percent, producing a negative output gap of about a half percentage point. Band-pass filters (Christiano-Fitzgerald and the Baxter-King filter) produce similar estimates of potential growth and output gap.

\section{Figure 1. Univariate Filters}

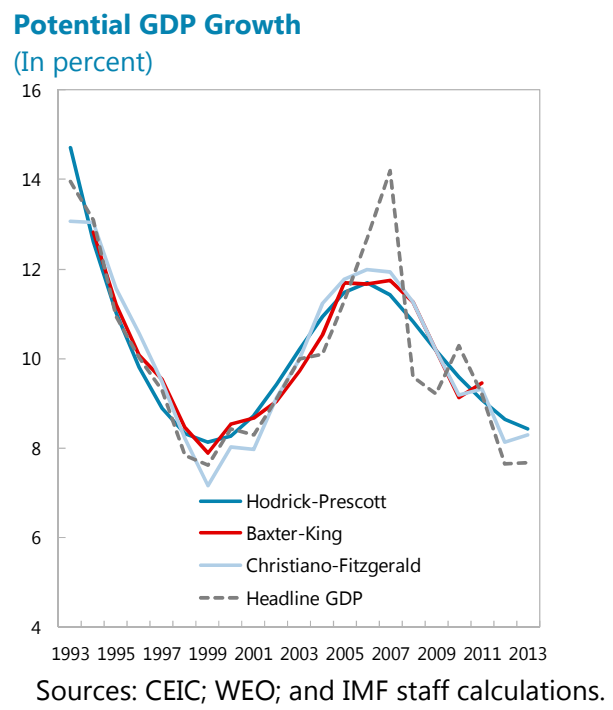

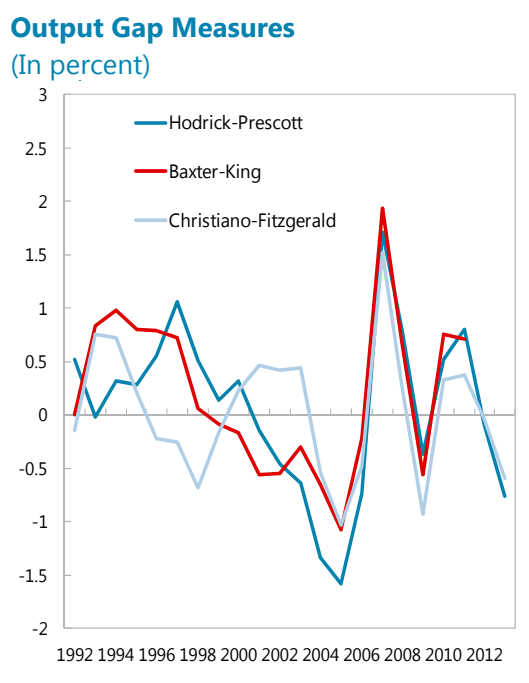


Estimates from multivariate filters (Figure 2) point to a steeper slowdown in potential GDP and output gaps closer to zero at the end of the sample. Inflation dynamics adds a significant amount of information at the beginning of the sample, when strong disinflation noticeably modifies the dynamics of the gap, generating negative estimates in the late 1990s. The impact is also visible around the year 2007, when the pickup in inflation is associated with the positive gap, and after the GFC, when inflation dropped to a negative level. As some inflationary pressures were coming from supply shocks (such as price liberalization reforms and food and commodity prices), the link between fluctuations in prices and output gap is visible more clearly when core inflation is used instead of the CPI. But output gaps constructed from multivariate filters are relatively small in absolute terms in both cases, suggesting that cyclical swings in output in the past two decades should not be interpreted as coming mainly from fluctuations in the traditionally defined output gap.

Figure 2. Multivariate Filters

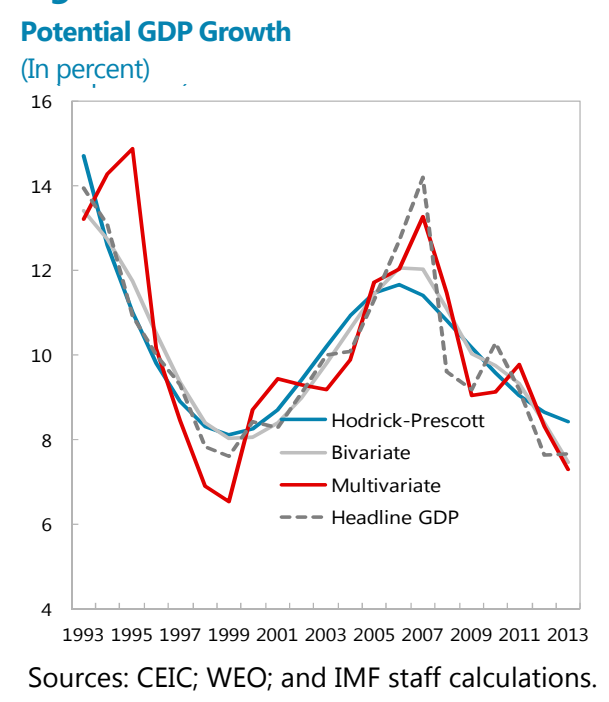

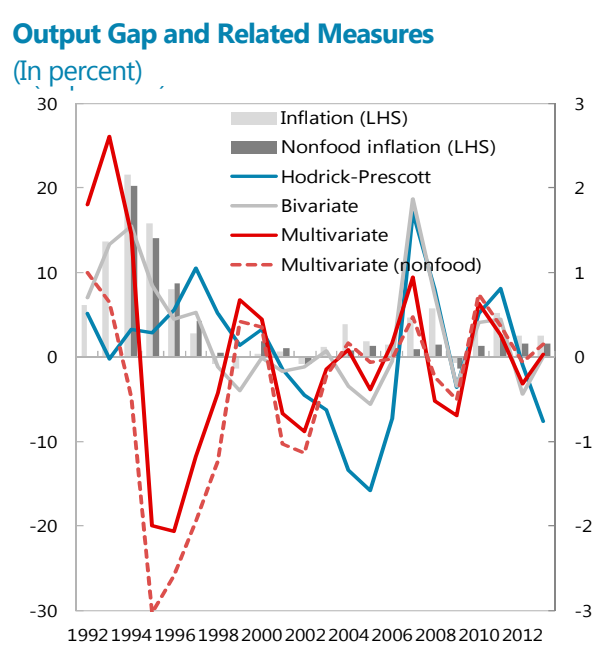

The production function approach inherits some properties from the multivariate filter, but shows a much lower output gap in 2013 (Figure 3). Similarly to the multivariate filter, the period of rapid disinflation in early 90's - typically interpreted as demand-driven (Keidel, 2008) - is associated with a negative output gap. However, unlike in results from the multivariate filter above, the gap turns persistently negative after the GFC. This dynamics is influenced by the addition of capacity utilization, as capital stock entering the production function is corrected by deviations of capacity utilization from its normal level (see Annex I for details). These deviations — plotted as the 'capacity utilization gap' on Figure 3-seem to drive output gap turning points in the model.

As reported elsewhere in the literature, the growth decomposition based on the production function approach indicates that the current potential output slowdown is largely driven by a significant drop in TFP growth, only partly offset by the higher contribution from capital. A similar slowdown has been observed around the time of the Asian crisis, with TFP growth bottoming out in 1999. 
Figure 3. Production Function Filter

Potential GDP Growth and Input Contributions (In percent),

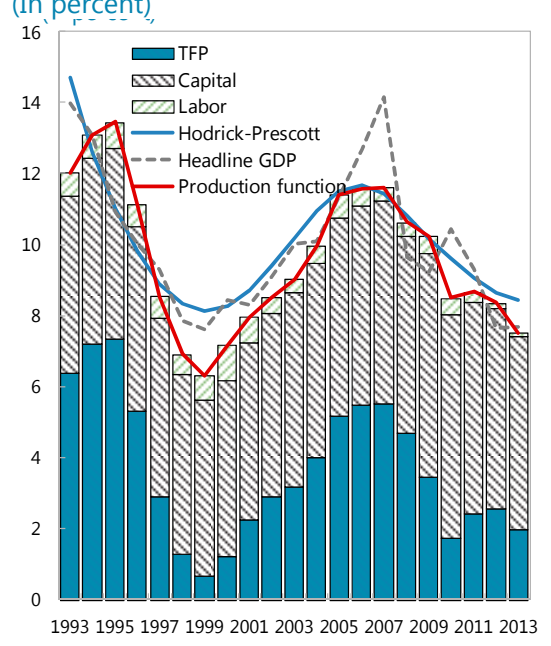

Sources: CEIC; WEO; and IMF staff calculations.

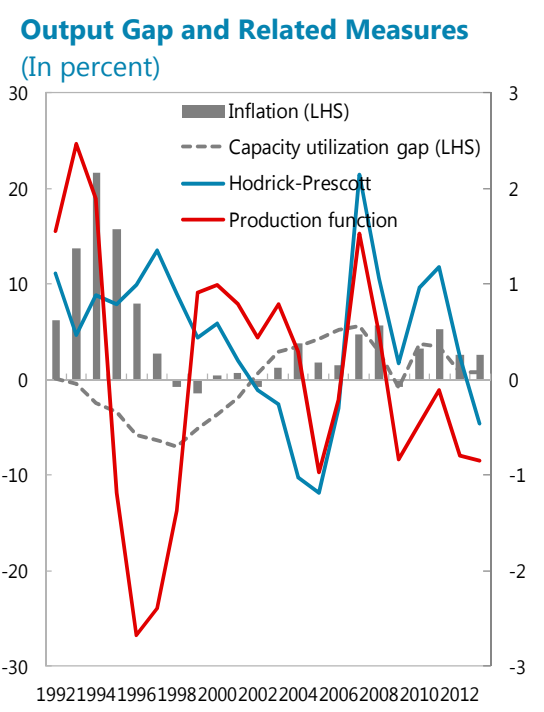

Our final approach estimates sustainable output and deviations from therein (Figure 4). The sustainable growth is slightly below the headline rate in 2013, but the deviation from sustainable output is positive and high, reflecting high headline growth rates after the GFC. The dynamics of deviations from sustainable output is strikingly different from series generated from other filters reported above. In particular, it produces a divergent post-GFC dynamics, driven by the surge in credit and rising housing prices.

Figure 4. 'Finance-Neutral' Filter Potential and Sustainable GDP Growth (In percent)

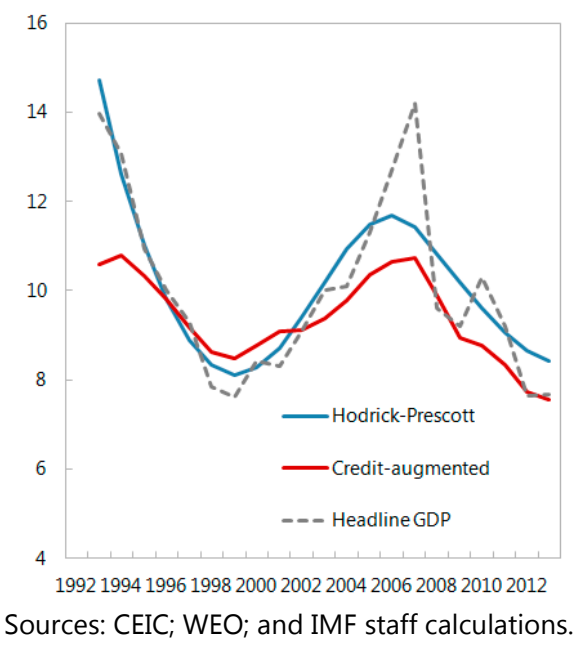

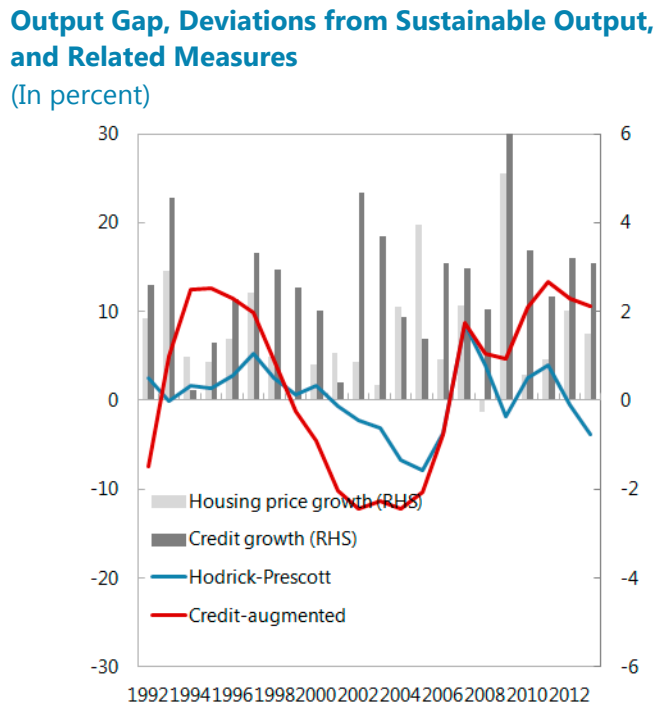




\section{Discussion}

Confusing as they may appear, the results from different methods have a clear economic interpretation:

- The key observation is that potential growth has slowed. While the dynamics throughout the sample vary across estimation methods, even the most optimistic estimates point to a secular character of the current slowdown, bringing potential growth below the headline in 2013.

- Output gap estimates linked to inflation or capacity utilization are close to zero or negative in 2013. This result holds after including information about unemployment (bivariate filter), inflation (multivariate filter) and capacity utilization (production function approach) in the model. The robustness is not surprising, given that both the subdued inflation dynamics and falling capacity utilization point to the opening of a negative gap. At the same time, the estimated gap is small, reflecting the fact that economy-wide deflationary pressures are contained. ${ }^{2}$

- Including financial-cycle information points to persistently positive deviations from sustainable output since 2007. The 2007 peak coincides with that identified above, and is a sign of exceptionally supportive global economic environment and loose monetary conditions in the pre-GFC period, but the increase in the gap after 2009 is very distinct from the dynamics identified by methods linking it to inflation and capacity utilization. It reflects the emergence of a credit gap arising from exceptionally strong credit growth, which was the key part of the post-crisis policy response.

How can the large difference between these results and the negative gap above be explained? We regard sustainability of demand and the structure of production as key factors driving the discrepancy:

- The traditional output gap has largely been closed through a massive stimulus in response to the negative shock from the GFC. On the demand side, the post-crisis stimulus relied on a combination of public and quasi-public investment, and loose monetary conditions supporting credit growth, particularly to real estate. These two demand engines were linked: SOEs were reportedly branching out to property development, incentivized by both soft guidelines to boost investment and by the profit motive given rising property prices (Deng and others, 2011). On the supply side, the stimulus absorbed the slack in the labor market created by the adverse shock related to the GFC, and promoted the addition of a new capacity in construction-related industries (such as steel, cement and glass). This

\footnotetext{
${ }^{2}$ Barnett and N'Diaye (2013) find a more negative output gap using a different measure of capacity utilization — a result that underscores uncertainty surrounding estimates of this key variable.
} 
demand and supply dynamics more or less closed the traditional output gap, which was close to zero when the stimulus was at its peak, and small and negative when it started fading away with the cooling of the real estate market. Regarding inflation, the stimulus initially helped to arrest deflationary pressures from the decline in external demand, although such pressures appear on the rise with output gap turning negative.

- But the credit-financed investment —one of the demand engines of the stimulus -is likely unsustainable ${ }^{3}$, which is reflected in the large 'finance-neutral' gap. In particular, the investment boom in the real estate has been sustained by a self-propelling cycle of rising asset prices and increasing demand, with access to financing facilitated by a rising value of real estate collateral and low interest rates. With a growing realization that demand could weaken and with some tightening of financial conditions (either because of deliberate policies or increasing risk aversion) conditions are ripe for an adjustment. Without offsetting measures, such an adjustment is likely to bring about a drop in creditfinanced development activities and a reassessment of projects started during the boom. Unprofitable projects - including in construction-related industries - will be mothballed, and resources reallocated to profitable opportunities under revised expectations, interest rates and prices. The identified deviation from sustainable output indicates than the current level of activity is above the path leading to such a new equilibrium. Moreover, it is likely that the traditional output gap will turn significantly negative during the adjustment (as production factors will be temporarily unemployed when shifting to new projects).

- Public and quasi-public sector investment - the second engine of the post-GFC stimulus - is a more stable source of demand, adding a cushion to the adjustment. However, even this support may prove unsustainable in the longer term, and efficiency consideration may outweigh their benefits in terms of stabilizing economic cycles. In particular, large public investment outlays are now possible because of exceptionally high household and corporate savings, which are often argued to result from economic distortions and the underdevelopment of a social safety net (Yang, 2012). Removing these distortions would likely lead to a higher consumption, but also raise interest rates. This could make some investment projects unprofitable and increase the burden of public debt, possibly damping the positive boost to demand from the higher consumption if the debt is allowed to grow too high. Moreover, it is possible that the future consumption needs will not be best served by the investment made today, as savings are directed to projects with a delayed payoff in terms of future consumption, such as infrastructure spending, housing supply in localities where demand is yet to come, and related industries. This investment may therefore become obsolete once the structure of demand is adjusted, either because the capital spending is misdirected or because it depreciates before it can be put into use.

\footnotetext{
${ }^{3}$ See Box 5 in IMF Country Report No. 14/235 for additional evidence.
} 
In conclusion, the different dynamics of traditional and finance-neutral gap measures has a clear economic interpretation, but the cyclical output fluctuations seem more connected to the financial cycle than the traditional business cycle, suggesting that a period of a slower growth may be needed to address imbalances accumulated in the post-GFC period. Output costs of the adjustment will depend on the flexibility of shifting resources to new profitable opportunities, which points to the importance of structural reforms to open up new activities (it appears that liberalizing reforms related to the WTO accession-see Bajona and Chu, 2010 - contributed to the strong recovery from the previous financial cycle). Such reforms are also critical to arrest the slowdown in potential output growth, identified in both approaches. We now turn to analyzing this slowdown and China's growth potential in more detail by looking at cross-country experience.

\section{Cross-Country Perspective: Catching Up With Asian Tigers?}

Despite doubts about the sustainability of their development model, the 'Asian Tigers' ultimately reached high-income status. Taiwan Province of China was growing at nearly 9 percent on average and growth in Japan and Korea averaged about $71 / 2$ percent for three post-war decades since the early 1950s. Growth moderated, but remained high, long after reaching the current level of China's per capita GDP, ultimately lifting their incomes per capita to above 70 percent of the U.S. level. Will China follow in their footsteps? 
Figure 5. Catching Up Process Relative to Fast-Growing Asia

Relative GDP growth performance

(GDP in constant 2005 prices; HP-filter trend; percent change)

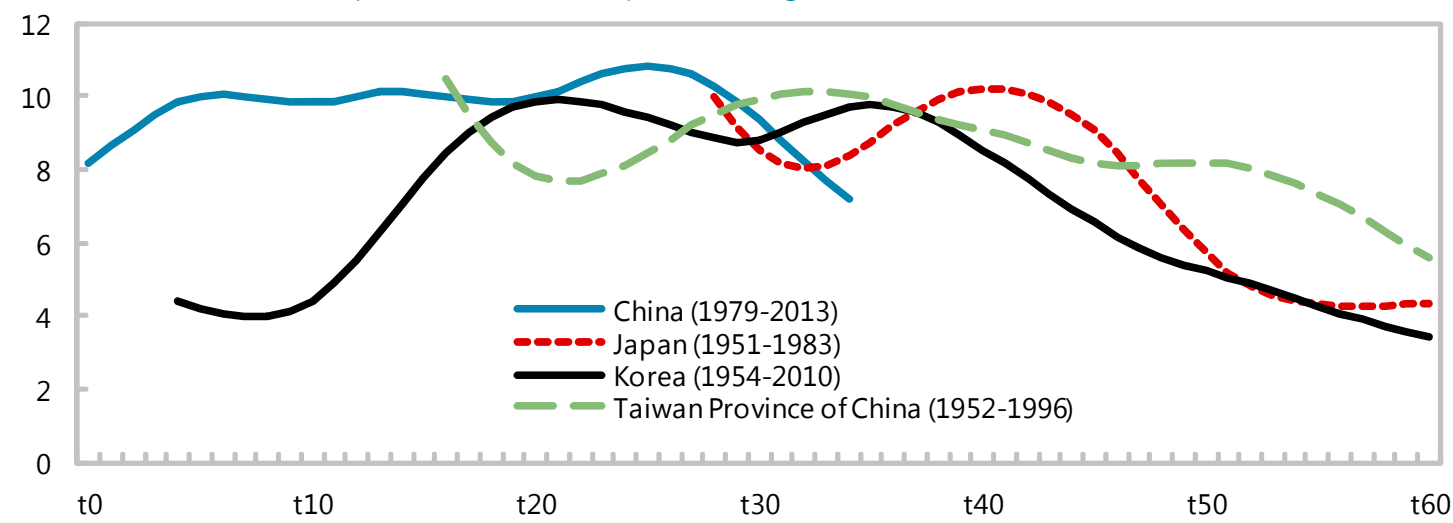

Catching up process relative to fast-growing Asia (per capita GDP in 2005 PPP prices relative to US level)

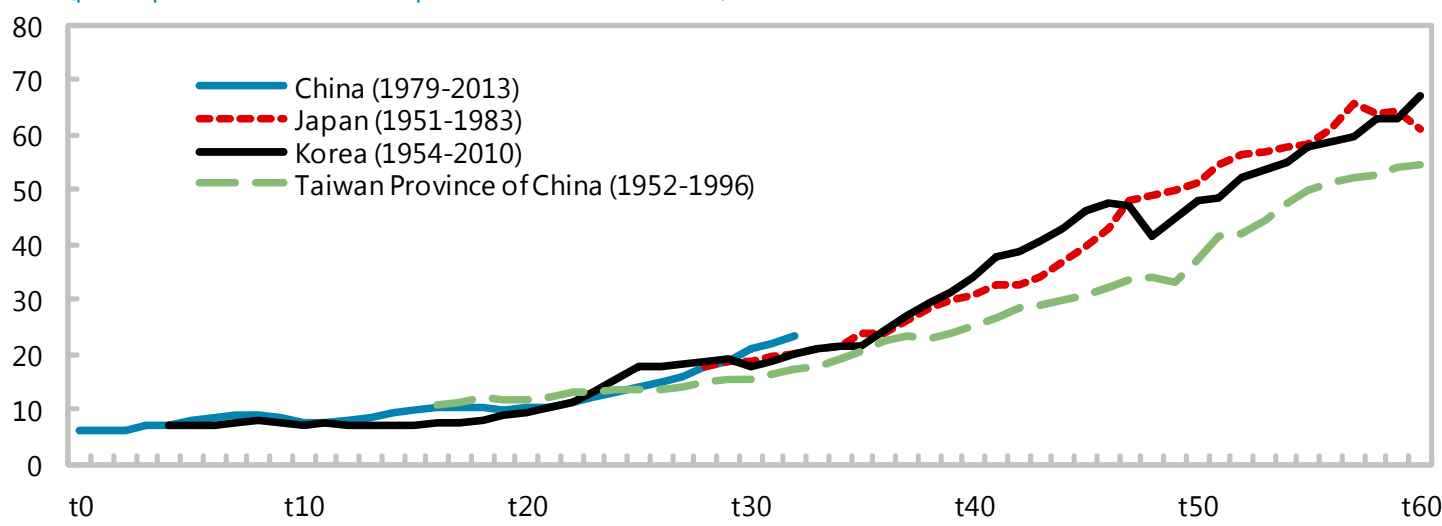

Growth in the catching up process (in percent)

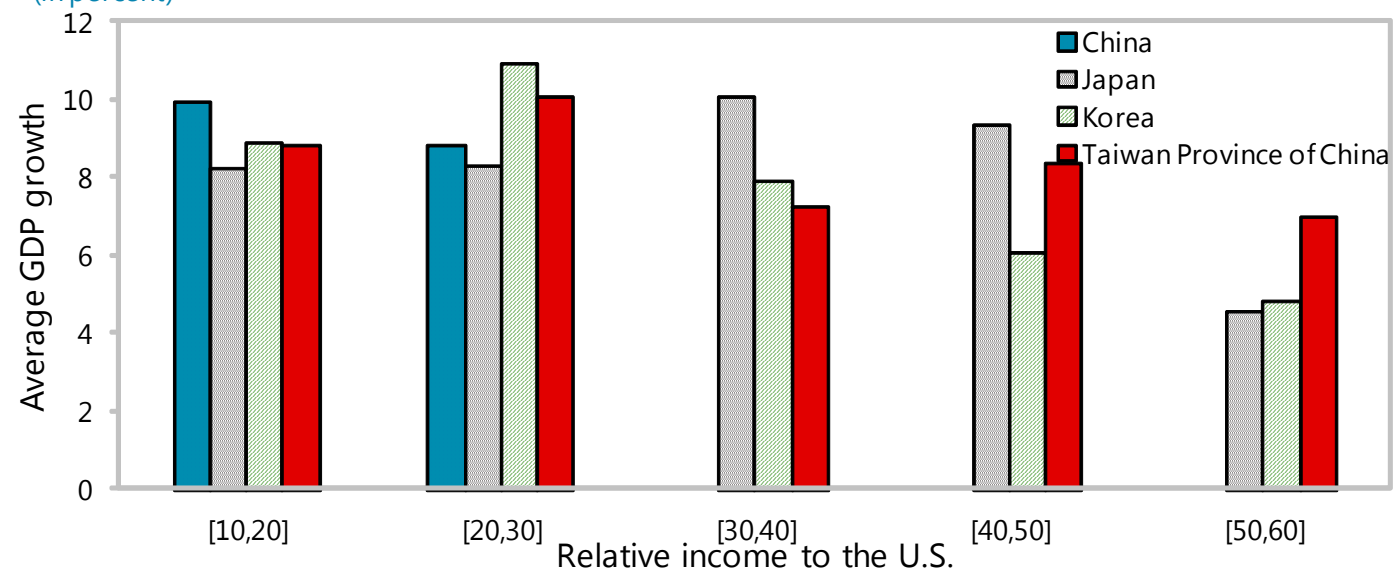

Sources: PWT 8.0; and WEO. 
The growth performance has been largely attributed to catching-up. Solow (1956) postulated that steady-state income per capita is a function of savings and population growth, and that per capita incomes converge to their country-specific steady-state levels, growing fast during the 'catching-up' phase. Productivity growth is determined exogenously in this model, but other strands of the growth literature similarly link productivity dynamics with the initial level of development. Gomulka (1990) distinguishes between economies with firms operating near the Technology Frontier Area (where productivity growth is determined by $R \& D$ and other investment in the generation of new ideas and patents) and those with companies located below. For the latter, productivity growth is largely dependent on the rate of technology transfer from outside and the internal capacity for absorption (Abramovitz 1986, Gomulka 1971, 1990, Verspagen 1991).

But 'catching-up' is not guaranteed, as it is often hindered by barriers reducing absorption capacity. Growth miracles may occur when barriers to technology absorption (such as trade restrictions and other distortions) are removed, and Parente and Prescott (2005) postulate that the fast growth in Japan, Korea, and Taiwan Province of China was the result of the liberal economic order - facilitating the absorption of technology — imposed by the United States in the post-war period. China's economic miracle, in their view, was the result of removing the corset of the central planning system and a gradual liberalization of the economy. While there is a consensus that economic liberalization played a key role in driving China's impressive growth in the 1980s and early 1990s, some authors still identify underdeveloped economic institutions, barriers to entry and mobility, and weak private property rights protection as significant obstacles to growth, particularly in the last two decades. Acemoglu and Robinson (2012) label the Chinese experience as growth under "extractive institutions", where even basic property rights are not respected. Pritchett and Summers (2014) point to low rankings in the World Bank's "Doing Business" indicators, in which China is below the median level in the overall "ease of business" and ranks near bottom when it comes to "starting a business".

Has the process of catching up in China been in line with the performance of 'Asian Tigers'? Figure 5 suggests that it has been broadly similar to the experience of the other fast growing economies, but we address this question more formally by comparing China's growth to the path implied by the convergence theory. To derive the theoretical path, we employ the standard Solow-based conditional convergence model from Aiyar and others (2013), where GDP per capita growth is regressed on the lagged income level and the lagged physical and human capital stock using a fiveyear panel regression for 138 countries from 19552009. The convergence path, however, is a function of barriers to the technology transfer as discussed above.
Figure 6. GDP Growth and Predicted Convergence Paths

(Percent change)

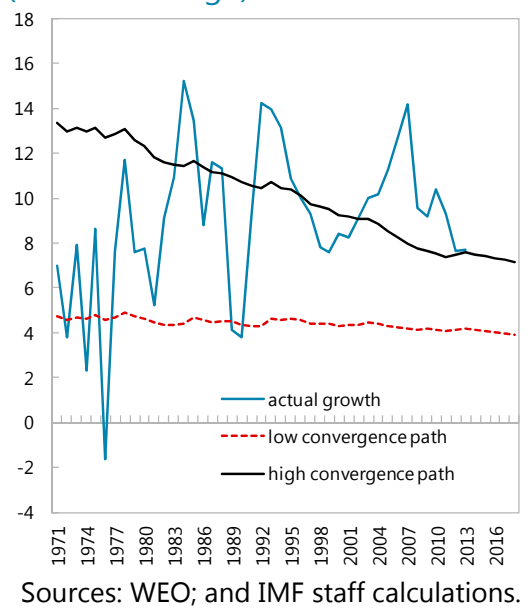


We therefore re-estimate the same model for the sample of "Asian Tigers" in order to construct the path that is more consistent with the successful catching-up experience in this group (this could be regarded as an upper bound of the convergence, with relatively lower barriers to the diffusion of technology boosting TFP growth). We then simulate theoretical convergence paths by substituting China's data to two versions of the estimated model. The actual growth path for China is significantly above the convergence path simulated from the full model ('low convergence path') and is oscillating around the Asian Tigers' path ('high-convergence path') since the dismantling of the strict central-planning system in 1979.

China's growth story has been highly successful, even by the standards of growth miracles from the past, but the results also confirm some more ominous facts about growth dynamics already identified in our earlier discussion on the potential output and output gap:

- Even the most optimistic model indicates a slowdown in the convergence-consistent growth. The model estimated on the Asian Tigers' data predicts growth to fall to about $71 / 2$ percent in 2013 - in line with the slowdown in potential growth obtained from various filtering methods above.

- Interpreting the convergence path as trend growth, we can identify cyclical fluctuations similar to filtering results presented above. In particular, periods of below-trend growth around 1998 are similar to fluctuations identified and discussed above. More importantly, the model indicates that growth has been well above the convergence trend in the late 2000s and has remained in the 'overheated' territory even after the relative slowdown in 2013.

Thus, not only the potential growth has slowed, but a period of below-trend growth is likely in light of the past cyclical pattern. As discussed above, such a slowdown is needed to reduce imbalances accumulated during the boom years. However, the paramount question is whether China will be able to stay at the 'high convergence path' in the long run.

It is important to notice that the convergence path of China might be different due to the size of its economy, which has necessitated a different growth model. For instance, both Korea and Taiwan Province of China managed to rely on an export-led growth model throughout their transition to high-income status. However, in PPP terms, these economies are respectively only about 10 percent and 6 percent of U.S. size in 2013. China, even with per capita income at about 20 percent of the U.S. level, is already equal to three-quarters of the U.S. economy and cannot rely to the same extent as other economies on external demand to fuel growth. The growth model has to be transformed to rely more on domestic demand and this process has already started since the GFC, as domestic demand has become the main source of growth, but it has been fueled largely by a strong increase in investment.

However, there are signs that the post-GFC surge in investment led to a significant drop in their efficiency. In particular, TFP growth in China is slowing. To illustrate this, we decompose potential growth in the sample of Asian Tigers and in China by smoothing TFP, 
capital, and labor inputs using the Hodrick-Prescott filter (for the ease of comparison we use a more standard production function method than estimates taking account capacity utilization discussed in the previous section, but results for China are broadly unchanged). We plot the decompositions starting from the same level of economic development for each economy, measured by per capita GDP in PPP prices. The results show that all fast-growing Asian economies relied heavily on capital accumulation (particularly in Taiwan Province of China), but the contribution of productivity growth was also significant (particularly in Japan throughout its high-growth episode). China's growth has followed a similar pattern, but the TFP contribution has been falling off in the post-2009 period (Figures 7 and 8). ${ }^{4}$ Moreover, the contribution from capital accumulation has also been declining despite a much higher share of investment in Chinese GDP, pointing to a declining marginal product of capital. While the capital-to-labor ratio in China is still much lower than in advanced economies, it is higher than among Asian Tigers when economies in this group were at the same level of development.

Transforming the growth model, while necessary, will therefore be challenging. First, the rise in investments has been unsustainable as the source of demand (the point we elaborate on when analyzing deviations from sustainable output in the previous section), which requires switching to consumption as the driver of demand. Moreover, the buildup of investment led to a reduction of efficiency, and maintaining high productivity growth in the domestically driven growth model will be particularly challenging. Export-oriented industries have been facing global competition and thus are likely to be more efficient than relatively more protected domestic sectors. Productivity growth - a critical ingredient in the catching-up dynamics — could therefore be lower in a domestically oriented growth model, especially without sufficient domestic competition. Relatively strong TFP growth has allowed China to follow in the footsteps of the 'Asian Tigers' so far. However, the 'Asian Tigers' graduation to high-income status required the strong TFP growth to persist well beyond China's current development stage.

\footnotetext{
${ }^{4}$ The results are influenced by our assumptions about input shares in the production function (derived from the average share of capital and labor incomes from PWT 8.0 data), which show a share of labor compensation in income in China of around one half. Applying more standard input shares in the production function produces a higher TFP contribution, but still indicates a falling trend in the post-2009 period.
} 
Figure 7. Contributions to Growth and Investment Shares

Investment Share

(in percent)

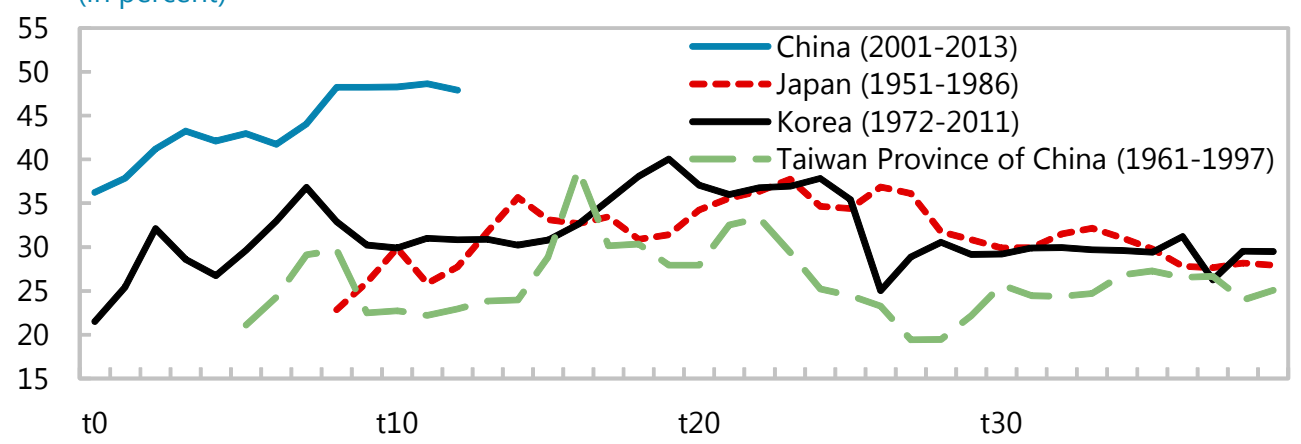

Capital Contribution to Growth (in percent)

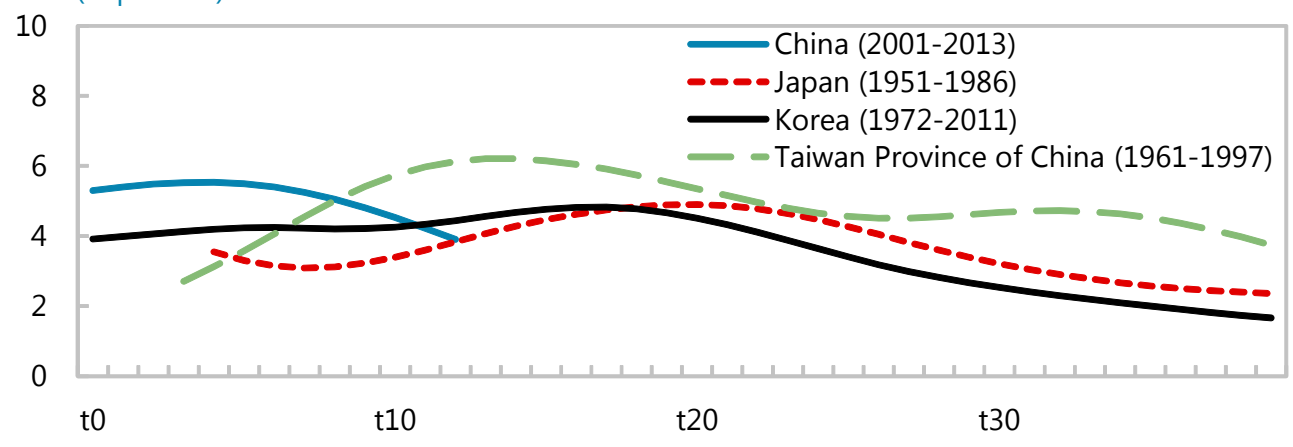

TFP Contribution to Growth

(in percent)

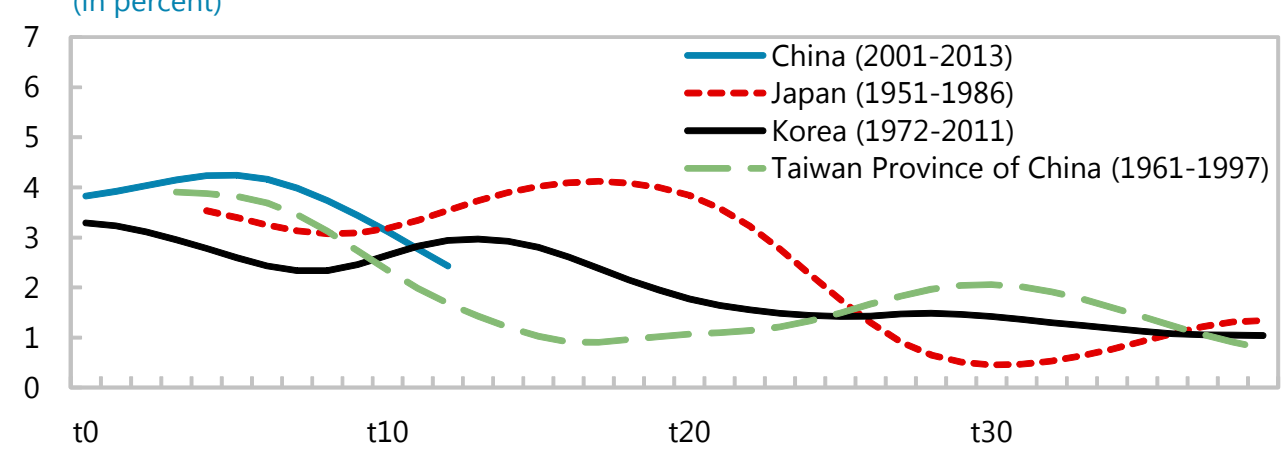

Sources: PWT 8.0; and WEO. 
Figure 8. Contribution to GDP Growth

(In percent)
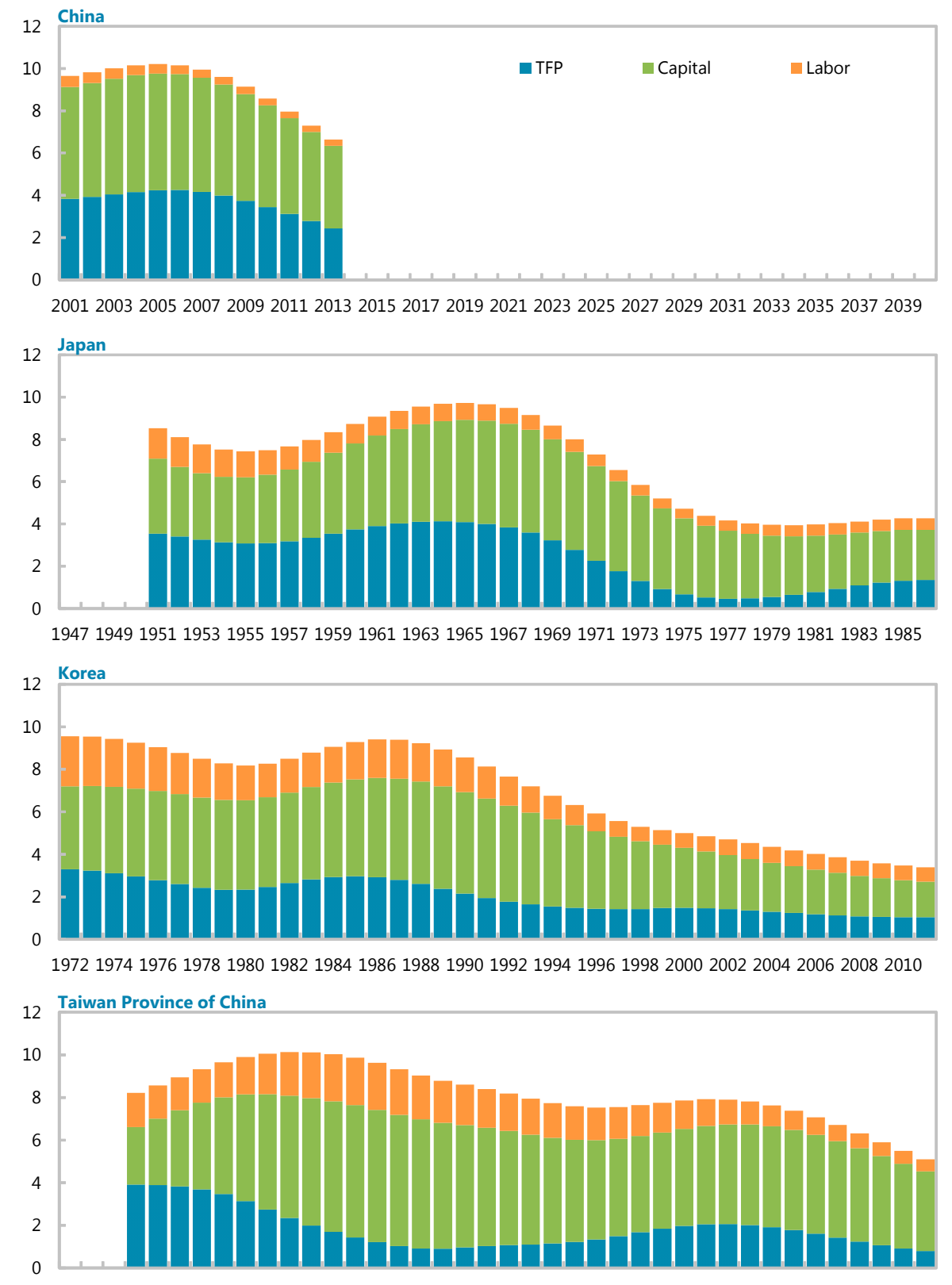

These findings do not bode well for growth prospects under the current growth model. Zhan, Jiang and Wang (2014) find that while TFP growth in China has been driven by the technological progress (which they found strongly linked to R\&D, education, and import of machinery), about half of these gains have been wiped out by various inefficiencies in the economy, which have likely increased with the recent investment drive. They also statistically confirm that the rapid credit growth has hindered the efficient allocation of capital and productivity growth. Looking from a cross-country perspective, Aiyar and others (2013) identify several economic characteristics increasing the probability of a persistent growth slowdown (or falling into a 'middle-income trap') and point to macroeconomic 
imbalances stemming from overinvestment - a prominent feature of the Chinese current domestically-oriented growth model — as key among them (Schumpeter, 1912; Minsky, 1986 and 1992).

Can economic reforms lead to a more efficient allocation of resources and unleash a wave of productivity growth in the domestically-oriented growth model? Lam and Maliszewski (2015) analyze potential productivity gains from the implementation of reforms announced in the 2013 Third Plenum reform blueprint. They conclude that a full implementation of the reform package would allow China to sustain long-term growth at the path broadly consistent with the experience of fast-growing Asian economies. It is also reassuring that the current slowdown in TFP growth is not unprecedented and previous downturns turned out to be temporary. Productivity growth used to rebound after new waves of liberalizing reforms, the latest one related to the WTO accession after the deep slowdown around 1998. But the lack of external anchor (such as the need to adapt to WTO requirements in the past) makes the current round of reforms more challenging.

There are risks associated with the reform process itself, which are specific to the institutional structure of the Chinese economy. Pritchett and Summers (2014) argue that the support currently provided for firms favored by the government create (selectively) a better business climate than the existing de jure regulatory environment. This generates conditions for fast growth, but there is a risk of a disorderly slowdown when the system is dismantled. Bai, Hsieh and Song (2014) identify in more detail key institutional foundations of growth under the current system: local governments' support for businesses connected to them (often for personal benefits), combined with a competition among local governments to attract successful businesses. The former helps overcome de jure restrictive regulations, while the latter prevents excessive capture of the state by vested interests. However, they point to inefficiencies and risks inherent in the system: entry barriers may eventually arise with a strengthening position of incumbents, and the allocation of public goods to support local business is inefficient. Potential benefits from successful reforms are therefore high, but rebuilding the system of economic incentives to create a more efficient system may be a lengthy and bumpy process.

\section{Conclusions}

Headline growth in China has slowed from the pre-GFC peak of 14 percent to less than 8 percent in 2013. China benefitted from the pre-crisis global expansion, but its export-based model suffered a blow when global demand collapsed. At the same time, the authorities embarked on a massive credit-cum-investment stimulus, which cushioned the impact of the global slowdown. The paper diagnoses the recent growth dynamics, identifying trend and cyclical factors, and evaluating long-term growth prospects. Our main findings are:

- Potential growth has slowed. While the dynamics throughout the sample vary across estimation methods, even the most optimistic estimates point to a secular character of the current slowdown, bringing potential growth below the headline rate in 2013. 
- Including financial-cycle information points to a relatively large positive 'finance-neutral' gap in 2013. It reflects imbalances accumulated in the economy since the GFC and linked to the exceptionally strong credit growth, which was the key part of the post-crisis policy response. The positive 'finance-neutral' gap should be interpreted as an indication that correcting the imbalances has costs in terms of output. Some of them are likely to be temporary (as production factors are redirected to other uses) and some permanent (as misallocated capital is depreciated after the adjustment). Fiscal policy can be an important stabilization tool in the adjustment, but its use has limits. A further accumulation of public debt could undermine sustainability, and possibly dampen the rise in consumption among some households if the tax burden to service the debt becomes excessive. There is also a risk of misallocating public investment to projects that will never be put to use.

- Traditional output gap estimates linked to inflation or capacity utilization are negative but small in 2013. The small gap reflects the fact that economy-wide deflationary pressures are contained, but, as explained above, this is underpinned by the equilibrium between demand and supply that is likely to be unstable. Stronger deflationary pressures could arise as the unsustainable demand contracts.

- Beyond the adjustment needed to correct the imbalances, long-term growth prospects remain strong, but with risks. The early part of catching up has been very successful, matching the experience of fast-growing 'Asian Tigers.' However, more recently productivity growth has slowed and there are signs of overinvestment. Moreover, the experience of other economies suggests that the quality of institutions could become an impediment to growth. This highlights the risk that growth could slow to a pace more consistent with the average of a broader group of emerging market economies.

- The Third Plenum reform blueprint put forward by the authorities has all necessary elements to keep China on the convergence path similar to the fast-growing Asian economies (and also to facilitate the adjustment after the credit boom). A steadfast implementation of reforms is the first line of defense against falling into a 'middleincome trap.' 


\section{Appendix I. Methodology}

\section{A. Univariate Filters}

\section{The Hodrick-Prescott Filter}

Hodrick-Prescott filter fits a trend line through sample observations $y$ by finding a trend output $\left(y^{*}\right)$ that minimizes a combination of the gap between the actual output and the trend output, and the rate of change in the trend output.

$$
\operatorname{Min} \sum_{t=1}^{T}\left(y_{t}-y_{t}^{*}\right)^{2}+\lambda \sum_{\mathrm{t}=2}^{\mathrm{T}-1}\left[\left(y_{t+1}^{*}-y_{t}^{*}\right)-\left(y_{t}^{*}-y_{t-1}^{*}\right)\right]^{2},
$$

where $\mathrm{T}$ is the sample size and $\lambda$ is a weighting factor that determines the degree of smoothness of the trend. A low value of $\lambda$ produces a trend that follows actual output more closely, whereas a high value of $\lambda$ reduces sensitivity of the trend to short term fluctuations in the actual output (in the limit the trend tends to the mean growth rate for the whole estimation period). Following the standard practice for annual data, we choose a smoothness parameter equal to 100 .

\section{Band Pass Filters}

Unlike the Hodrick-Prescott filter, which is a high-pass filter (removes low frequency cycles from the data), the band-pass filter takes a two-sided weighted moving average of the data, filtering out cyclical fluctuations outside a pre-specified frequency band. The filter is based on the idea that business cycles can be defined as fluctuations of a certain frequency. Fluctuations with a higher frequency are considered as irregular or seasonal, those of lower frequency are associated with the trend, and the medium-frequency component is considered to be the cyclical component or the business cycle. Given that the true frequency of the business cycle is not precisely defined, the filter extracts frequencies within a relatively broad frequency range.

We use two different types of band-pass filters - Baxter-King filter and Christiano-Fitzerald filter. Standard practice using these filters assumes a cycle lasts from two to eight years. In particular, Baxter-King is a fixed length symmetric filter, where the weights for lags and leads (of same length) are the same and time-invariant. Christiano-Fitzerald filter is a full sample asymmetric filter, where the weights on the leads and lags are allowed to differ and is time-varying.

\section{Baxter King Band Pass Filter}

The band pass filter designed by Baxter and King (1995) passes through the components of time series with fluctuations between six (18 month) and 32 (96 month) quarters, removing higher and lower frequencies. The moving average weights depend only on the band 
specification, and do not use the data. Specified leads/lags of 8 quarters, the filter is thus a weighted moving average of leads/lags up to 8 quarters. The weights are symmetric for leads and lags and time-invariant. By choosing specified leads/lags (K), results in a loss of $\mathrm{K}=8$ observations both in the beginning and in the end of the series. But choosing low values for $\mathrm{K}$ results in poor approximation of the filter to the ideal high pass filter.

\section{Christiano-Fitzgerald (CF) Filter}

The Christiano-Fitzgerald random walk filter is a band pass filter that was built on the same principles as the Baxter and King (BK) filter. While BK filter is constrained to produce stationary filters, the data has to be made stationary before applying CF filter. Here we remove the linear trend in real GDP. The band for business cycle is chosen as eight to 32 quarters (same as BK). It is worth noting that the weights in CF can differ for leads and lags, and is also time-varying with the weights depending on the data and changing for each observation. ${ }^{5}$ Unlike BK, the filter is a moving average of the full sample.

These filters formulate the de-trending and smoothing problem in the frequency domain. Both the BK and CF filters approximate the ideal infinite band pass filter. The Baxter and King version is a symmetric approximation, with no phase shifts in the resulting filtered series. But symmetry and phase correctness comes at the expense of series trimming. Depending on the trim factor a certain number of values at the end of the series cannot be calculated. There is a trade-off between the trimming factor and the precision with which the optimal filter can be approximated. On the other hand the Christiano-Fitzgerald filter uses the whole time series for the calculation of each filtered data point. The advantage of the $\mathrm{CF}$ filter is that it is designed to work well on a larger class of time series than the BK filter, converges in the long run to the optimal filter, and in real time applications outperforms the BK filter. For details, see Christiano-Fitzgerald (1999).

\section{B. Multivariate Filters Linking Output Gap to Inflationary Pressures}

The unobserved components model is a method to estimate the unobserved variables such as potential output, trend growth rate and output gap using the information from observed variables. Once the model is specified in the state space form, values of unobserved variables can be computed by a recursive algorithm known as the Kalman filter, conditional on the initial values for the unobserved state vector and other parameters of the model. Under certain conditions the Kalman filter allows for a construction of a likelihood function, which

\footnotetext{
${ }^{5} \mathrm{CF}$ also has a version of fixed-length symmetric filter, but the moving average weights are different due to different objective function when select the weights.
} 
can be evaluated using classical or Bayesian methods. In what follows, we define various multivariate models used for deriving unobservable output gap and potential output series. These models are put in a state-space form and estimated by a Bayesian regularized maximum likelihood method (Ljung, 1999). It is important to acknowledge that our estimates are sensitive to the choice of priors given relatively short time series and noisy data. To assess the robustness of results to priors, we estimate the bivariate model with a regular maximum likelihood method.

\section{Bivariate Model}

In this model, the output $y$ is decomposed into two independent components: a permanent trend component (potential GDP), $\bar{y}$ and a cyclical component (output gap) $y^{\text {gap }}$

$$
y_{t}^{g a p}=\bar{y}_{t}+y_{t}^{g a p}
$$

The permanent trend is modeled as local linear trend.

$$
\begin{gathered}
\bar{y}_{t}=\bar{y}_{t-1}+g_{t-1} \\
g_{t}=g_{t-1}+\varepsilon_{t}^{g}
\end{gathered}
$$

The cyclical component of GDP is assumed to be stationary and follows an autoregressive process $\operatorname{AR}(1)$

$$
y_{t}^{g a p}=\theta y_{t}^{g a p}+\varepsilon_{t}^{y^{g a p}},
$$

It is also assumed to be linked to inflation $(\pi)$ in a backward looking Phillips curve:

$$
\pi_{t}=\alpha \pi_{t-1}+\beta y_{t-1}+\varepsilon_{t}^{\pi}
$$

Data: Quarterly GDP and inflation data from WEO database, CEIC, and Haver Analytics.

\section{Multivariate Model}

This model, developed by Benes and N'Diaye (2010), is built around three gaps - the output gap $(y)$, the unemployment gap $(u)$, and the capacity utilization gap $(c)$ - and three identifying equations:

The inflation equation relates the level and the change of the output gap to inflation:

$$
\pi 4_{t}=\pi 4_{t-1}+\beta y_{t}^{g a p}+\Omega\left(y_{t}^{g a p}-y_{t-1}^{g a p}\right)+\varepsilon_{t}^{\pi 4} \text {. }
$$


Based on Okun's law, an unemployment equation links the unemployment gap to the output gap:

$$
u_{t}^{g a p}=\emptyset_{1} u_{t-1}^{g a p}+\emptyset_{2} y_{t}^{g a p}+\varepsilon_{t}^{u}
$$

Given the three identifying equations, the equilibrium variables are assumed to evolve dynamically as follows. A stochastic process including transitory (level) shocks and more persistent shocks guides the evolution of equilibrium unemployment $(\bar{u})$ (the NAIRU equation):

$$
\bar{u}_{t}=\bar{u}_{t-1}+g_{t}^{\bar{u}}-\frac{\omega}{100} y_{t-1}^{g a p}-\frac{\lambda}{100}\left(\bar{u}_{t-1}-u^{S S}\right)+\varepsilon_{t}^{\bar{u}}
$$

Persistent shocks to the NAIRU $\left(g_{t}^{\bar{u}}\right)$ follow an autoregressive process:

$$
g_{t}^{\bar{u}}=(1-\alpha) g_{t-1}^{\bar{u}}+\varepsilon_{t}^{g^{\bar{u}}}
$$

And trend output $(\bar{y})$ is modeled to include a time-varying growth rate $\left(g^{\bar{Y}}\right)$ and to depend changes in the NAIRU. Specifically:

$$
\bar{y}_{t}=\bar{y}_{t-1}-\theta\left(\bar{y}_{t}-\bar{y}_{t-1}\right)-(1-\theta)\left(\bar{u}_{t-1}-\bar{u}_{t-20}\right) / 19+g_{t}^{\bar{y}} / 4+\varepsilon_{t}^{\bar{y}}
$$

where $\theta$ is the labor share in a Cobb-Douglas production function. A similar dynamic equation is specified for equilibrium capacity utilization.

Finally, an output gap equation is added to recognize the fact that monetary policy exerts its influence on inflation through the output gap:

$$
y_{t}^{g a p}=\rho_{1} y_{t-1}^{g a p}-\frac{\rho_{2}}{100}\left(\pi 4_{t-1}-\pi 4_{t-1}^{E}\right)+\varepsilon_{t}^{y^{g a p}},
$$

where $\pi 4_{t-1}^{E}$ is the inflation expectation.

Data: Quarterly GDP and inflation data are from the WEO database, inflation expectation is from Consensus Economics Forecast. Capacity utilization and unemployment rate data are from CEIC.

\section{Multivariate Filter with the Addition of a Production Function}

This model builds on Barnett and N'Diaye (2013) and augments the multivariate model above by adding a Cobb-Douglas-type production function, linking potential output to trend employment and the stock of capital adjusted for capacity utilization.

The first three equations for the output, unemployment and capacity gaps closely resemble the specification of the multivariate model described above:

$$
\begin{gathered}
\pi_{t}=\lambda \pi_{t-1}+(1-\lambda) \pi_{t+1}+\beta y_{t}^{g a p}+\varepsilon_{t}^{\pi} . \\
u_{t}^{g a p}=\varphi_{1} u_{t-1}^{g a p}+\varphi_{2} y_{t}^{g a p}+\varepsilon_{t}^{u^{g a p}} .
\end{gathered}
$$




$$
c_{t}^{g a p}=\kappa_{1} c_{t-1}^{g a p}+\kappa_{2} y_{t}^{g a p}+\varepsilon_{t}^{c^{g a p}} .
$$

Where the unemployment and capacity gaps are again defined as deviations from potential values modeled as stochastic trends specified as follows:

$$
\begin{aligned}
& \bar{u}_{t}=\bar{u}_{t-1}+\varepsilon_{t}^{\bar{u}} \\
& \bar{c}_{t}=\bar{c}_{t-1}+\varepsilon_{t}^{\bar{c}} .
\end{aligned}
$$

The dynamics of output is derived from the production function, which links labor and capital inputs with a stochastic process for productivity growth.

The labor input depends on the unemployment rate (specified above), combined with the dynamics of population $(n)$ :

$$
\Delta n_{t}=\zeta \Delta n^{S S}+(1-\zeta) \Delta n_{t-1}+\varepsilon_{t}^{\Delta n}
$$

The participation rate $(p)$ is decomposed into a gap and a potential participation, modeled as a stochastic trend:

$$
\begin{gathered}
p_{t}^{g a p}=\theta_{1} p_{t-1}^{g a p}+\theta_{2} y_{t-1}+\varepsilon_{t}^{p^{g a p}} . \\
\bar{p}_{t}=\bar{p}_{t-1}+\varepsilon_{t}^{\bar{p}} .
\end{gathered}
$$

The population and the participation rate together define a labor force:

$$
l f_{t}=n_{t}+p_{t}
$$

With the potential participation defining a potential labor force:

$$
\overline{l f}_{t}=n_{t}+\bar{p}_{t}
$$

The potential labor input $(\bar{e})$ is then constructed from the first order expansion of the equilibrium unemployment $(\bar{u})$ around its steady-state value $u^{s s}$ :

$$
\bar{u}_{t}-u^{s s} \approx-\left(1-\frac{u^{s s}}{100}\right) *\left(\bar{e}_{t}-\overline{l f}_{t}-100 * \log \left(1-\frac{u^{s s}}{100}\right)\right)
$$

The growth in capital stock $(\Delta k)$ is defined as a stationary $\mathrm{AR}(1)$ process around a steadystate growth $\left(\Delta k^{S S}\right)$ :

$$
\Delta k_{t}=\gamma \Delta k^{S S}+(1-\gamma) \Delta k_{t-1}+\varepsilon_{t}^{\Delta k}
$$

And the equilibrium capital input is a function of the capital input and equilibrium capacity utilization: 


$$
\overline{k_{t}}=k_{t}+\overline{c_{t}} .
$$

Finally, total factor productivity $(\bar{a})$ follows a stochastic trend with a time-varying slope $(g)$ :

$$
\begin{gathered}
\bar{a}_{t}=\bar{a}_{t-1}+g_{t}+\varepsilon_{t}^{a} \\
g_{t}=\tau g^{S S}+(1-\tau) g_{t-1}+\varepsilon_{t}^{g} .
\end{gathered}
$$

And the potential output is constructed by combining production factors in the Cobb-Douglas production function:

$$
\bar{y}_{t}=\overline{a_{t}}+\alpha \overline{e_{t}}+(1-\alpha) \bar{k}_{t} .
$$

Data: Annual GDP and inflation data are from the WEO database. Capacity utilization and unemployment rate data are from CEIC. Capital and labor data are from PWT 8.0.

\section{Multivariate Filter to Estimate 'Finance-Neutral' Output Gap}

Derivation of the 'finance-neutral' output gap is also based on a multivariate filter. In addition to the output gap, we define a credit gap $\left(c^{g a p}\right)$ and a housing price gap $\left(h p^{g a p}\right)$. The output gap is assumed to react to the credit gap, and potential output $(\bar{y})$ follows as stochastic trend with a time varying slope $\left(g^{\bar{y}}\right)$ :

$$
\begin{gathered}
y_{t}^{g a p}=\varphi_{1}^{y} y_{t-1}^{g a p}-\varphi_{2}^{y} c_{t}^{g a p}+\varepsilon_{t}^{y^{g a p}} \\
\bar{y}_{t}=\bar{y}_{t-1}+g_{t}^{\bar{y}}+\varepsilon_{t}^{\bar{y}} \\
g_{t}^{\bar{y}}=g_{t-1}^{\bar{y}}+\varepsilon_{t}^{g^{\bar{y}}}
\end{gathered}
$$

The credit gap is similarly defined as deviation of a real credit from stochastic trends $(\bar{c})$, which contains a time varying slope $\left(g^{\bar{c}}\right)$ :

$$
\begin{gathered}
c_{t}^{g a p}=\varphi_{1}^{c} c_{t-1}^{g a p}+\varepsilon_{t}^{c^{g a p}} \\
\bar{c}_{t}=\bar{c}_{t-1}+g_{t}^{\bar{c}}+\varepsilon_{t}^{\bar{c}} \\
g_{t}^{\bar{c}}=g_{t-1}^{\bar{c}}+\varepsilon_{t}^{g^{\bar{c}}}
\end{gathered}
$$

Finally, the housing price gap equation links the housing gap with the credit gap ('excess' credit is assumed to cause deviations of real housing prices from their equilibrium). ${ }^{6}$ Equilibrium housing prices follow stochastic trends $(\overline{h p})$ with a time varying slope $\left(g^{\overline{h p}}\right)$ :

$$
h p_{t}^{g a p}=\varphi_{1}^{h p} h p_{t-1}^{g a p}-\varphi_{2}^{h p} c_{t}^{g a p}+\varepsilon_{t}^{h p^{g a p}}
$$

\footnotetext{
${ }^{6}$ Adding the housing price gap as a regressor in the 'finance-neutral' output gap equation significantly widens posterior densities of the coefficients, which is likely due to colinearity between credit and housing price gaps.
} 


$$
\begin{gathered}
\overline{h p}_{t}=\overline{h p}_{t-1}+g_{t}^{\overline{h p}}+\varepsilon_{t}^{\overline{h p}} \\
g_{t}^{\overline{h p}}=g_{t-1}^{\overline{h p}}+\varepsilon_{t}^{g^{\overline{h p}}}
\end{gathered}
$$

Data: Annual GDP and inflation data are from the WEO database. Credit data are from BIS (credit to the private sector). Housing price data are from CEIC.

\section{E. Production Function Approach for Cross-Country Analysis}

We use the aggregate Cobb-Douglas production function with input shares $(\alpha)$ estimated based on the time-varying share of labor in income.

$$
Y_{t}=A_{t} K_{t}^{\alpha} L_{t}^{(1-\alpha)}
$$

Where $Y_{t}$ represents GDP in period t, $K_{t}$ the physical capital stock, $L_{t}$ the labor component, and $A_{t}$, the total factor productivity which embodies the efficiency with which factor inputs are used, such technological progress and other determinants.

This approach contains the following steps:

Step 1: derive historical TFP as output less weighted average of factor inputs. Factor input weights are estimated from average income shares of capital and labor.

Step 2: using HP filter to derive trend TFP growth

Step 3: using HP filter to derive trend growth of physical capital stock

Step 4: derive trend labor using working age population

Step 5: trend output is derived using trend TFP, trend labor and physical capital stock.

Data: Annual data from PWT 8.0. 


\section{REFERENCES}

Abramovitz, Moses, 1986, "Catching Up, Foreign Ahead, and Falling Behind," Journal of Economic History, Vol. 46, pp. 385-406.

Acemoglu, D. and J. Robinson, 2012, Why Nations Fail: The Origins of Power, Prosperity, and Poverty (Crown Business).

Aiyar, S., R. Duval, D. Puy, Y. Wu, and L. Zhang, 2013, "Growth Slowdowns and the MiddleIncome Trap,” IMF Working Paper No 13/71 (Washington: International Monetary Fund).

Albert M., Jude, C., Rebillard, C., 2015, “The Long Landing Scenario: Rebalancing from Overinvestment and Excessive Credit Growth, and Implications for Potential Growth in China," mimeo.

Bai, C., Hsieh, C., and Y. Qian, 2006, "The Return to Capital in China," Brookings Papers on Economic Activity, No. 2, pp. 61-101.

Bajona, C. and T. Chu, 2010, "Reforming State Owned Enterprises in China: Effects of WTO Accession," Review of Economic Dynamics, Vol. 13, No. 4, pp 800-23 (Elsevier, October).

Benes, J., and P. N'Diaye, 2004, “A Multivariate Filter for Measuring Potential Output and the NAIRU: Application to the Czech Republic," IMF Working Paper No. 04/45 (Washington: International Monetary Fund).

Eckaus, R., 2014, “Forced Savings in China,” MIT Department of Economics Working Paper No. $14-10$.

Gerlach, S. and W. Peng, 2006, "Output Gaps and Inflation in Mainland China,” BIS Working Papers 194 (Basel: Bank for International Settlements).

Deng, Y., R. Morck, J. Wu, and B. Yeung, 2011, “China’s Pseudo-Monetary Policy,” Review of Finance.

Gomulka, Stanislaw, 1971, "Inventive Activity, Diffusion and the Stages of Economic Growth," Monograph No.24, (Aarhus: Aarhus University).

Gomulka, S., 1990, “The Theory of Technological Change and Economic Growth,” (London and New York: Routledge)

Hoffman, D. and A. Polk, 2014, "The Long Soft Fall in Chinese Growth Business Realities, Risks and Opportunities," Conference Board Research Report. Available via the Internet: https://www.uschina.org/china-hub/report-long-soft-fall-chinese-growth

Haberler, G., 1932, "Money and the Business Cycle," in Gold and Monetary Stabilization, ed. by Q. Wright (New Jersey: Wiley).

International Monetary Fund, 2014, IMF Country Report, No. 14/235 (Washington). 
JP Morgan, 2009, “China’s Goldilocks Economy. The Congee May Be 'just right,"” JP Morgan Insights (October).

Keidel, A., 2008, “China's Economic Fluctuations: Implications for its Rural Economy, 2008.” Available via the Internet:

www.carnegieendowment.org/files/keidel_china_fluctuations_final.pdf

Krugman, P., 1994, “The Myth of Asia's Miracle,” Foreign Affairs, Vol. 73, No. 6 (Nov/Dec).

Lam, W. and W. Maliszewski, forthcoming, "Giving Credit for China's Slowdown: Assessing the Impact of the Third Plenum Reforms," IMF Working Paper (Washington: International Monetary Fund).

Liao, C, and W. Maliszewski, forthcoming, “China's Credit Boom” IMF Working Paper (Washington: International Monetary Fund).

Minsky, H., 1986, Stabilizing an Unstable Economy (New Haven: Yale University Press).

Page, J., 1994, "The East Asian Miracle: Four Lessons for Development Policy,” NBER Macroeconomics Annual, Vol. 9, pp 219-82 (Cambridge: National Bureau of Economic Research).

Parente, S. L., and E. C. Prescott, 2005. "A Unified Theory of the Evolution of International Income Levels," in Handbook of Economic Growth, ed. by Philippe Aghion and Steven Durlauf, Vol. 1, pp. 1371-416 (Elsevier, $1^{\text {st }}$ ed.).

Scheibe, J., 2003, “The Chinese Output Gap During the Reform Period 1978-2002," Economics Series Working Papers 179, University of Oxford, Department of Economics.

Tian, Xu, T. and Y. Xiaohua, 2012, "The Enigmas of TFP in China: A Meta-Analysis," China Economic Review, Vol. 23, No. 2, pp. 396-414.

Verspagen, B., 1991, “A New Empirical Approach to Catching Up or Falling Behind," Structural Change and Economic Dynamics, Vol. 2, No. 2, pp 359-80.

Wu, H., 2014, “China's Growth and Productivity Performance Debate Revisited-Accounting for China's Sources of Growth with a New Data Set," Conference Board Working Paper, EPWP No. 14 (February).

Xie, A., 2013, "Pick Your Poison," Caixin Online (October 28). Available via the Internet: http://english.caixin.com/2013-10-28/100596446.html.

Yang, D., 2012, “Aggregate Savings and External Imbalances in China,” Journal of Economic Perspectives, Vol. 26, No. 4, pp. 125-46 (American Economic Association, fall).

Young, A., 1995, "The Tyranny of Numbers: Confronting the Statistical Realities of the East Asian Growth Experience," Quarterly Journal of Economics, Vol. 110, No. 3, pp. 641-80 (August). 
Zhang, C., B. Zhang, Z. Lu, and Y. Murasawa, 2013, “Output Gap Estimation and Monetary Policy in China," Emerging Markets Finance and Trade, Vol. 49, No. S4, pp. 119-31 (September).

Zhang, J., C. Jiang, and P. Wang, 2014, 'Total Factor Productivity and China's Miraculous Growth: An Empirical Analysis’ (draft). 